\title{
Does curve magnitude in adolescent idiopathic scoliosis (AIS) affect frequency and quality of sport participation? A feasibility study
}

Michael Youssef', John Soliman', Sarah Burrow ${ }^{2}$, Waleed Kishta ${ }^{2}$, Nicole Simunovic ${ }^{3}$, Andrew Duong ${ }^{3}$, Olufemi R. Ayeni ${ }^{2,3}$ and Devin Peterson ${ }^{2 *}$

\begin{abstract}
Background: This pilot study explores whether large adolescent idiopathic scoliosis (AIS) curves $\left(\geq 45^{\circ}\right.$ ) lead to decreased frequency and quality of sport participation, lower health-related quality of life (HRQL), and more pronounced shortness of breath (SOB) as compared to smaller curvatures $\left(<45^{\circ}\right)$.

Methods: Patients were divided into two groups based on their spinal curvature: Cobb angle $<45^{\circ}(n=31)$ and $\geq$ $45^{\circ}(n=21)$. We assessed feasibility outcomes including agreement to be approached, participation, recruitment rates and missing data. All participants completed five questionnaires to assess the frequency and quality of sport participation, HRQL and SOB outcomes. Estimates of effects 95\% confidence intervals (Cls) were reported.

Results: This study enrolled 52 surgically untreated AIS patients between the ages of 10 and 18 (44 females, 8 males, mean age $=14.60)$. All feasibility threshold criteria were successfully met $(100 \%$ agreement to be approached, 100\% participation with $n \geq 12$ in each group, and $94.2 \%$ of patients without missing data). AIS patients with large curvatures $\left(\geq 45^{\circ}\right)$ trended towards decreased frequency and quality of sport participation, more pronounced SOB and worse HRQL outcomes, as compared to patients with smaller curve sizes.

Conclusion: The study findings show that a study addressing sport participation in the setting of AIS is feasible. The size of curvature in AIS may have an impact on sport participation, HRQL and SOB, but larger studies are required.
\end{abstract}

Keywords: Adolescent idiopathic scoliosis, Curve size, Sport participation, Health-related quality of life, Shortness of breath

\footnotetext{
* Correspondence: dpeters@mcmaster.ca

${ }^{2}$ Division of Orthopaedic Surgery, Department of Surgery, McMaster University, Hamilton, ON, Canada

Full list of author information is available at the end of the article
}

(c) The Author(s). 2021 Open Access This article is licensed under a Creative Commons Attribution 4.0 International License, which permits use, sharing, adaptation, distribution and reproduction in any medium or format, as long as you give appropriate credit to the original author(s) and the source, provide a link to the Creative Commons licence, and indicate if changes were made. The images or other third party material in this article are included in the article's Creative Commons licence, unless indicated otherwise in a credit line to the material. If material is not included in the article's Creative Commons licence and your intended use is not permitted by statutory regulation or exceeds the permitted use, you will need to obtain permission directly from the copyright holder. To view a copy of this licence, visit http://creativecommons.org/licenses/by/4.0/ The Creative Commons Public Domain Dedication waiver (http://creativecommons.org/publicdomain/zero/1.0/) applies to the data made available in this article, unless otherwise stated in a credit line to the data. 


\section{Key messages regarding feasibility}

- Many uncertainties exist regarding the feasibility of conducting a large-scale study exploring the magnitude of AIS curve size on sport participation and health outcomes. Firstly, little research has been published on this research question, and thus, there is a lack of scoliosis-specific questionnaires that measure the outcomes of interest. This raises concerns regarding the feasibility of using non-scoliosis questionnaires to assess the study outcomes. Secondly, the study uses many questionnaires which can be time-consuming. Thus, it is unclear whether patients would be willing to participate in the study or if results would yield substantial missing data. Lastly, the feasibility of recruiting untreated AIS patients with curves above $45^{\circ}$ needs to be determined in the clinical setting, considering that such patient population would rarely go untreated as they progress to such severity. Determining recruitment rates is important to know whether it is realistic to recruit large sample sizes in this patient population before committing resources to a large-scale study.

- Key feasibility findings include $100 \%$ agreement to be approached, $100 \%$ patient participation, 52 patients recruited over 2 months exceeding the success threshold criteria for recruitment rates, 94.2\% of patients completed the study questionnaires and measurements without missing data and in less than $15 \mathrm{~min}$.

- Findings from this study support the feasibility of recruiting a large sample size and conducting a large-scale powered study to further explore the research question. Furthermore, results indicate that the study procedures and tools are feasible to use in the clinical setting and can be used to explore the severity of scoliosis and its impact on sport participation and health outcomes.

\section{Background}

Adolescent idiopathic scoliosis (AIS) constitutes approximately $90 \%$ of all scoliosis cases in children and youth [1]. AIS literature has primarily focused on the impact of the disease on respiratory and health-related quality of life (HRQL) outcomes. However, there has been a paucity of literature regarding its impact on sport participation, an integral part of adolescents' lifestyle, specifically, how AIS affects the frequency and quality of sport engagement [2].

Curve magnitude is of particular importance in AIS as it dictates the severity of the condition. A curve size of $45^{\circ}$ is a standard threshold that categorizes mild/moderate curves from severe ones [3]. Studies conducted on AIS patients have demonstrated that a large curvature is implicated in increasing shortness of breath (SOB) and worsening $\mathrm{HRQL}$ outcomes such as pain and self-image concerns [4-8]. However, other studies have shown that curve magnitude had no effect on HRQL $[9,10]$.

The benefits of sport participation in adolescents are many including developing friendships and discipline and collaborating with others. The ability of patients with AIS to participate in sport has been very underreported. With regards to sport participation, one study found no relationship between curve magnitude and sport frequency in untreated AIS patients, and there are no studies on the quality of sport participation [2].

The purpose of this study is to determine the feasibility of studying sport participation in patients with severe AIS and suggest potential modifications to the procedures used in order to more fully capture this population in future studies. Additionally, this study explores whether AIS patients with curve sizes $\geq 45^{\circ}$ tend to experience decreased frequency and quality of sport participation, lower HRQL, and more pronounced SOB during activity as compared to patients with smaller curves.

\section{Methods}

The aim of this pilot study is to assess the feasibility of studying sport participation in patients with severe AIS and to explore potential trends regarding the impact of AIS curve size on sport participation, HRQL and SOB outcomes.

\section{Study population}

This cross-sectional pilot study enrolled 52 AIS patients who had not had deformity surgery ( 44 females, 8 males) between the ages of 10 and 18 (mean age $=14.6$ ) over a period of 2 months. Patients were divided into two groups based on their spinal curvature: Cobb angle $<45^{\circ}$ $(n=31)$ and $\geq 45^{\circ}(n=21)$. Cobb angles were calculated using the largest of the proximal thoracic (PT), main thoracic (MT) or thoracolumbar/lumbar (TL-L) components [9]. All curves were considered if they were at least $10^{\circ}$ or more in magnitude and were then classified as proximal thoracic $(\mathrm{PT})$, main thoracic (MT) or thoracolumbar/lumbar (TL/L).

\section{Setting and recruitment}

Patients were recruited from the Orthopedic clinic at McMaster Children's Hospital in Hamilton, Ontario, Canada. Ethics approval was obtained from the Hamilton Integrated Research Ethics Board (HiREB \#3989). Eligible participants were screened during their regular clinic visit by their orthopaedic surgeon and parents were asked by the clinic staff for verbal consent prior to their child being approached for participation. 
The team then explained the study rationale and obtained informed consent for participation.

\section{Eligibility criteria}

Inclusion criteria included patients between the ages of 10 and 18 who were diagnosed with AIS and had not undergone surgical management of their deformity. Participants had to be able to speak, understand, and read the language of the clinical site. As minors, participants had to provide both assent and parental consent. Patients were excluded if they had any of the following as their primary diagnosis: kyphosis, spondylolisthesis, spina bifida or any developmental disabilities that limit the participant's ability to understand the questionnaires.

\section{Feasibility outcomes}

The following a priori thresholds were used to assess feasibility measures:

1. Agreement to be approached: more than $80 \%$ of eligible patients agree to hear about the study from the research team.

2. Agreement to participate: more than $80 \%$ consent to participate from all patients who agreed to hear about the study.

3. Recruitment rates: 24 subjects recruited within 2 months (12 in each group). A sample size of 12 participants per group is a common convention used for pilot studies if there is no prior information to base a sample size on [11].

4. Missing data: more than $80 \%$ of participants, who consent for participation, complete all questionnaires without missing data.

All participants were timed as they complete the questionnaires to provide more accurate information regarding the time commitment required by patients.

\section{Questionnaires (Additional file 1: Appendix)} Assessment of sport participation frequency-sport score A Sport Score questionnaire as described by Noyes et al. [12] was used for sport participation [12]. This questionnaire explores the frequency of engaging in sport and the intensity of the sport played. A maximum score is 100 indicating 4-7 days/week participation in strenuous sports such as basketball or soccer.

\section{Assessment of sport participation quality- $P O D C I$}

Items relevant to the quality of sport activity from the self-reported version of the Pediatric Outcomes Data Collection Instrument (PODCI) were used to determine the quality of sport participation. The score for each item ranges from 1 to 4 with lower numbers indicating higher sports functioning. A total mean score was calculated for each participant by adding scores from individual items [13].

Assessment of respiratory symptoms-MRC and UCDQ

Two respiratory questionnaires, the Medical Research Council (MRC) Breathlessness scale and the University of Cincinnati Dyspnea Questionnaire (UCDQ), were used to determine whether $\mathrm{SOB}$ was encountered during sport participation [14, 15]. When scoring MRC and UCDQ, patients select a grade from 1 to 5 to describe their SOB, with lower grades indicating better respiratory function [14-16]. With regards to UCDQ, only 4 relevant items were adopted from the original questionnaire and a mean score was calculated. When patients selected "not interested" for any of the activities listed on the UCDQ questionnaire, the score for the individual item was not factored in calculating the average score.

\section{Assessment of HRQL-SRS-22r}

The Scoliosis Research Society (SRS-22r) questionnaire, a reliable and valid assessment tool, was used to explore the overall HRQL score [16]. Additionally, subdomain scores including function, pain, self-image, mental health and satisfaction scores were reported [17]. The scoring system of the SRS-22r is published elsewhere [17].

Cobb angles were measured by one of the participating paediatric orthopaedic surgeons, and potential confounders including physiotherapy, bracing and body mass index (BMI) were also recorded.

\section{Descriptive data analysis}

Percentages were calculated for all feasibility outcome measures. Average means, standard deviations (SD) and estimates of effects (95\% CIs) were reported for all patient-reported variables and outcomes.

\section{Results \\ Feasibility outcomes}

All a priori feasibility measures outlined above were successfully met. All 59 patients approached by the clinic staff agreed to hear about the study from the research team (100\% agreement to be approached). Of those who were approached by the research team and had their eligibility confirmed $(n=52)$, all consented to participate in the study (100\% participation). Recruitment rate exceeded the success threshold, where a total of 52 participants were recruited over a period of 2 months $(n=$ 31 for the $<45^{\circ}$ group; $n=21$ for the $\geq 45^{\circ}$ group). Of the 52 patients recruited, 49 patients answered all the questionnaires and had complete measurements without any missing data (94.2\%), thereby exceeding the success threshold. With regards to timing, $94.2 \%$ of patients completed the study in $15 \mathrm{~min}$ or less with an average time of $11.71 \pm 3.10 \mathrm{~min}$. 


\section{Participant recruitment}

The process by which participants were recruited is outlined in Fig. 1. Over a period of two months, 67 untreated AIS patients were identified by the clinic staff. A total of eight eligible patients were missed in this study and were never approached by the study team. Of the 59 patients who were approached, seven patients were excluded after application of the inclusion/exclusion criteria. Reasons for exclusion were a diagnosis of spondylolisthesis $(n=1)$, spina bifida $(n=2)$, congenital scoliosis $(n=1)$ and developmental disabilities $(n=3)$.

\section{Baseline demographic data}

Table 1 reports demographic characteristics of the study population. Participants were predominantly female (female $=48$, male $=8$ ) with a mean age of 14.6. This is representative of the AIS population demographic, where females generally have a higher incidence and severity of the disease compared to males, with literature suggesting a 7.2:1 female to male ratio in curves $>40^{\circ}$ [1]. The average Cobb angle was $23.34^{\circ}$ in the $<45^{\circ}$ group and $56.9^{\circ}$ in the $\geq 45^{\circ}$ group. Nineteen patients of the $\geq 45^{\circ}$ group had an MT curve size $\geq 45^{\circ}$.

Fourteen patients $\left(n=8\right.$ in the $<45^{\circ}$ group; $n=6$ in the $\geq 45^{\circ}$ group) indicated their use of a brace for an average of $15.75 \mathrm{~h}$ daily, with no observable differences between groups. Additionally, 15 patients reported receiving one or more treatment(s) for their back, including physiotherapy $(n=9)$, osteopathy $(n=2)$, chiropractic $(n=3)$, acupuncture $(n=1)$ and stretches $(n=2)$. Physiotherapy was the most common intervention with an average of $3.28 \mathrm{~h} /$ week, and no major differences between groups. The mean BMI for the study sample was 20.69 , and there were no major differences between groups (19.70 for the $<45^{\circ}$ group; 22.10 for the $\geq 45^{\circ}$ group).

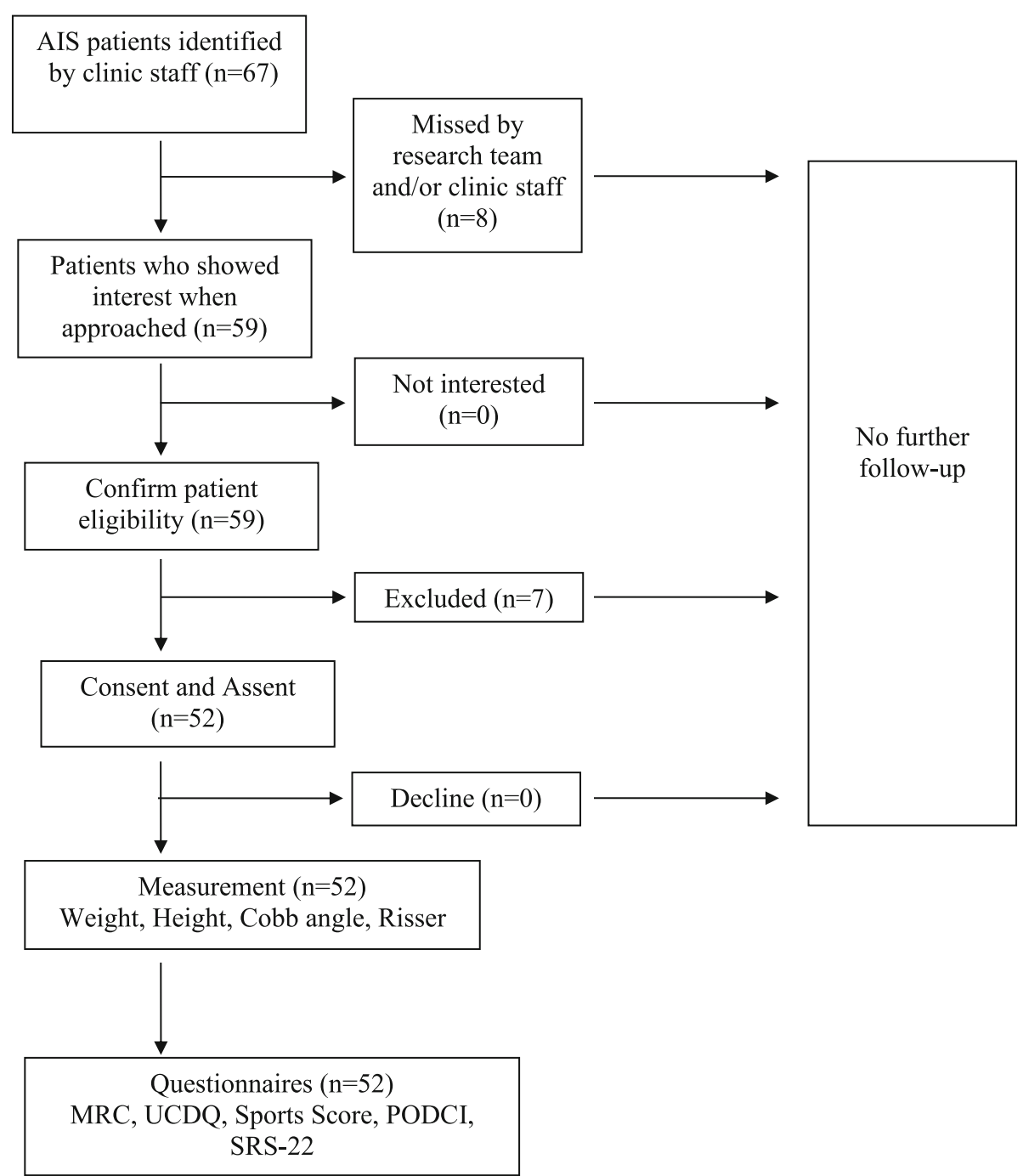

Fig. 1 Patient recruitment model 
Table 1 Study population demographics

\begin{tabular}{|c|c|c|c|}
\hline & Cobb angle $<45^{\circ}(n=31)$ & Cobb angle $\geq 45^{\circ}(n=21)$ & Overall $(n=52)$ \\
\hline Age, years (mean $\pm S D$ ) & $14.16 \pm 1.55$ & $15.24 \pm 1.76$ & $14.60 \pm 1.71$ \\
\hline Gender, $n$ (male/female) & $5 / 26$ & $3 / 18$ & $8 / 44$ \\
\hline Weight, kg (mean \pm SD) & $53.32 \pm 9.25$ & $60.88 \pm 15.59$ & $56.43 \pm 12.69$ \\
\hline Height, cm (mean \pm SD) & $164.16 \pm 10.16$ & $165.84 \pm 9.61$ & $164.84 \pm 9.88$ \\
\hline PT angle $\left(^{\circ}\right)($ mean \pm SD) & $11.02 \pm 7.27$ & $29.65 \pm 11.73$ & $18.33 \pm 12.98$ \\
\hline MT angle $\left(^{\circ}\right)($ mean $\pm \mathrm{SD})$ & $17.90 \pm 11.19$ & $54.88 \pm 12.72$ & $33.13 \pm 21.80$ \\
\hline$T L / L$ angle $\left(^{\circ}\right)($ mean, $\pm S D)$ & $18.37 \pm 10.27$ & $40.30 \pm 10.52$ & $27.23 \pm 14.95$ \\
\hline Cobb angle $\left(^{\circ}\right)$ (mean \pm SD) & $23.34 \pm 9.46$ & $56.9 \pm 10.15$ & $36.89 \pm 19.22$ \\
\hline Risser sign & $3.56 \pm 1.73$ & $3.71 \pm 1.51$ & $3.63 \pm 1.63$ \\
\hline
\end{tabular}

PT proximal thoracic, $M T$ main thoracic, $T L / L$ thoracolumbar/lumbar

\section{Patient-reported outcomes}

\section{Frequency and quality of sport participation}

Table 2 shows the results of the sport outcomes explored in this study. Data suggests a trend towards greater curvature being associated with both decreased frequency and quality of sports participation. On the PODCI questionnaire, 9 patients described not participating in sports for the reasons of dislike of sports $(n=$ 8 ) or pain while playing sports $\left(n=1\right.$; in the $\left.\geq 45^{\circ}\right)$.

\section{Sob}

The results regarding $\mathrm{SOB}$ as measured by both the MRC and UCDQ questionnaires are shown in Table 3. Patients with greater curvatures trended towards experiencing more SOB during sport participation.

\section{$H R Q L$}

HRQL outcomes were assessed using the SRS-22r questionnaire, and total and subdomain scores are shown in Table 4. Generally, there were trends with greater curvature being associated with increased pain and self-image concerns as well as decreased function and satisfaction with treatment measures. Furthermore, there was a generally higher SRS22 total score in the below $45^{\circ}$ group reflecting better HRQL as compared to patients with more severe curvatures.

Table 2 Sports outcomes

\begin{tabular}{|c|c|c|}
\hline & $\begin{array}{l}\text { Below } 45^{\circ} \\
\text { group } \\
\text { Mean } \pm \mathrm{SD} \\
(95 \% \mathrm{Cl})\end{array}$ & $\begin{array}{l}\text { Above } 45^{\circ} \\
\text { group } \\
\text { Mean } \pm \mathrm{SD} \\
(95 \% \mathrm{Cl})\end{array}$ \\
\hline $\begin{array}{l}\text { Frequency of sport participation } \\
\text { (Sport Score) }\end{array}$ & $\begin{array}{l}74.68 \pm 25.36 \\
(65.8-83.6)\end{array}$ & $\begin{array}{l}69.05 \pm 24.01 \\
(58.8-79.3)\end{array}$ \\
\hline $\begin{array}{l}\text { Quality of sport participation } \\
\text { (PODCI) }\end{array}$ & $\begin{array}{l}1.27 \pm 0.39(1.13- \\
1.41)\end{array}$ & $\begin{array}{l}1.48 \pm 0.49(1.27- \\
1.69)\end{array}$ \\
\hline
\end{tabular}

\section{Discussion}

This is a pilot study designed to explore the feasibility of conducting a larger study that assesses the impact of curve size in AIS patients on the frequency and quality of sport participation. The most significant finding was that all feasibility criteria were successfully met, supporting the efficacy of the study tools and protocols. The feasibility component of the study suggests that largerscale trials can be performed as patients were interested in participating and the burden of time to complete the questionnaires is very reasonable. Generally, data suggests a trend towards greater curvatures being associated with decreased frequency and quality of sport participation. This suggests that AIS patients with a large curve size $\left(\geq 45^{\circ}\right)$ might face more functional limitations when participating in sports than those with lesser curve magnitude.

A Cobb angle of $50^{\circ}$ or greater at skeletal maturity has been found to be a predictor of decreased pulmonary function and patients with curves between 60 and $100^{\circ}$ have been found to have a total lung capacity $68 \%$ of normal $[18,19]$. In the current study, patients with larger curves appear to have more SOB on the MRC questionnaire and similar to findings from Danielsson et al. [20]. They also had similar results on the UCDQ questionnaire, further supporting the association between curve size and SOB.

The relationship between curve magnitude and HRQL outcomes, in AIS literature, has largely been inconclusive with conflicting results. A study by Climent et al. showed that curve magnitude is associated with worse

Table 3 Shortness of breath (SOB) outcomes

\begin{tabular}{|c|c|c|}
\hline Questionnaire & $\begin{array}{l}\text { Below } 45^{\circ} \text { group } \\
\text { Mean } \pm \mathrm{SD}(95 \% \mathrm{Cl})\end{array}$ & $\begin{array}{l}\text { Above } 45^{\circ} \text { group } \\
\text { Mean } \pm \text { SD }(95 \% \mathrm{Cl})\end{array}$ \\
\hline$\overline{M R C}$ & $1.26 \pm 0.44(1.1-1.42)$ & $1.52 \pm 0.68(1.23-1.81)$ \\
\hline UCDQ & $2.33 \pm 0.89(2.01-2.65)$ & $2.55 \pm 1.05(2.08-3.02)$ \\
\hline
\end{tabular}


Table 4 SRS-22r total and subdomain scores

\begin{tabular}{llr}
\hline Domain & $\begin{array}{l}\text { Below } \mathbf{4 5}^{\circ} \text { group } \\
\text { Mean } \pm \text { SD (95\% Cl) }\end{array}$ & $\begin{array}{c}\text { Above } \mathbf{4 5} \text {. } \\
\text { Mroun } \pm \text { SD (95\% Cl) }\end{array}$ \\
\hline SRS22r pain & $4.28 \pm 0.64(4.06-4.5)$ & $4.26 \pm 0.69(3.96-4.55)$ \\
SRS22r function & $4.52 \pm 0.44(4.36-4.67)$ & $4.32 \pm 0.65(4.04-4.6)$ \\
SRS22r self-image & $4.01 \pm 0.62(3.79-4.23)$ & $3.60 \pm 0.84(3.24-3.96)$ \\
SRS22r mental health & $3.84 \pm 0.79(3.56-4.12)$ & $3.85 \pm 0.94(3.45-4.25)$ \\
SRS22r satisfaction & $4.05 \pm 0.77(3.78-4.32)$ & $3.98 \pm 0.73(3.67-4.29)$ \\
SRS22r total & $4.15 \pm 0.49(3.98-4.32)$ & $4.00 \pm 0.66(3.72-4.28)$ \\
SRS22r total (w/o satisfaction) & $4.16 \pm 0.51(3.98-4.34)$ & $4.01 \pm 0.68(3.72-4.30)$ \\
\hline
\end{tabular}

SRS22 Scoliosis Research Society

pain, function, self-image, mental health, satisfaction and total SRS scores [21]. However, other studies have shown no correlations between curve size and the aforementioned health-related outcomes [22-24]. In our pilot study, there were trends towards more significant pain and self-image concerns with lower functioning and satisfaction in the greater curvature group. This makes the results more consistent with studies like that by Climent et al. but larger more powered studies are needed to further explore those important outcomes.

This pilot study has several strengths. First, it is one of few studies addressing a very important part of an adolescent's life, sport participation. Second, the recruitment rate suggests that there is interest in both patients and caregivers to explore issues relating to AIS and sport participation. The recruitment rate was robust and enables planning for future properly powered studies addressing this topic. Part of the success in recruitment stems from the multidisciplinary team involved in both recruitment and patient interaction, as well as the limited burden posed by the study procedures. With an overall prevalence of $0.5-5 \%$ [1], there would be little problem in performing a large-scale study of this population. In fact, AIS is the most common spinal deformity seen by primary care doctors and spine surgeons [25], thus ensuring a continued high recruitment rate for a larger-scale study. Furthermore, many patients completed the study tools during their normal wait-time, avoiding any extra time commitment beyond their routine care. The standard deviation (SD) of the Sport Score questionnaire was calculated to be 24.7 which is an important parameter for calculating a sample size for future powered studies; however, other studies are needed to find the minimal clinically important difference (MCID) of this tool. Both parameters are required to calculate an appropriate sample size for future powered studies exploring the frequency of sport participation as a primary outcome.

The study has several limitations to consider. First, the research team was not able to be present due to other commitments for a total of eight patients who were therefore not recruited for the study. Recruitment can be further improved by ensuring a larger number of research staff who can cover more of the clinic's working hours. Second, some of the questionnaires utilized are not spinespecific tools, and thus, there might be concerns about their validity in the context of AIS. However, the Sport Score questionnaire has been used by Parsch et al. [2] in their scoliosis study. Finally, this feasibility study only reports "trends" and potential associations between curve size and sports and health-related outcomes. Larger studies will be required to further explore those associations and draw more conclusive findings.

\section{Conclusion}

This study suggests that larger-scale trials can be reasonably performed as patients were interested in participating and the burden of time to complete the questionnaires is reasonable. The preliminary findings show trends suggesting that a large spine curvature $(\geq$ $45^{\circ}$ ) may be associated with decreased frequency and quality of sport participation, increased SOB during activities and worse HRQL outcomes. However, the inherent limitations of pilot studies require that future high-powered research be conducted to further explore this research question.

\section{Supplementary Information}

The online version contains supplementary material available at https://doi. org/10.1186/s40814-020-00745-4.

Additional file 1: Questionnaires (Appendix 1).

\section{Abbreviations}

AIS: Adolescent idiopathic scoliosis; HRQL: Health-related quality of life; SOB: Shortness of breath; PT: Proximal thoracic; MT: Main thoracic; TLL: Thoracolumbar/lumbar; PODCl: Pediatric Outcomes Data Collection Instrument; MRC: Medical Research Council; UCQD: University of Cincinnati Dyspnea Questionnaire; SRS: Scoliosis Research Society; BMI: Body mass index; SD: Standard deviation; Cl: Confidence intervals; MCID: Minimal clinically important difference 


\section{Acknowledgements}

The study team would like to thank the Orthopedic department at McMaster Children's Hospital, Hamilton, ON, Canada, for allowing access to their patients and the staff for their cooperation and assistance with data collection. Sincere thanks are also extended to all patients who took part in this study.

\section{Authors' contributions}

DP conceived the idea of the study. DP, MY and JS designed the study and protocol. DP, SB and WK assisted in the recruitment of participants and in filling diagnostic data forms. MY and JS collected, analysed and interpreted the data. NS and AD helped with data analyses. MY and JS prepared the first draft of the manuscript. DP and OA critically revised and edited successive drafts of the manuscript. All authors reviewed the final manuscript and approved it for publication.

\section{Funding}

Not applicable.

\section{Availability of data and materials}

The datasets used and/or analysed during the current study are available from the corresponding author on reasonable request.

\section{Ethics approval and consent to participate}

Ethics approval was granted by the Hamilton Integrated Research Ethics Board (HiREB).

REB Project ID\#: 3989

The ethical principles of ensuring voluntary participation, fully informed consent, and the right to withdraw from research participation were applied.

\section{Consent for publication}

Not applicable.

\section{Competing interests}

The authors declare that they have no competing interests.

\section{Author details}

${ }^{1}$ Faculty of Health Sciences, McMaster University, Hamilton, ON, Canada. ${ }^{2}$ Division of Orthopaedic Surgery, Department of Surgery, McMaster University, Hamilton, ON, Canada. ${ }^{3}$ Department of Health Research Methods, Evidence and Impact, McMaster University, Hamilton, ON, Canada.

Received: 3 March 2020 Accepted: 15 December 2020

Published online: 12 January 2021

\section{References}

1. Konieczny MR, Senyurt H, Krauspe R. Epidemiology of adolescent idiopathic scoliosis. J Child Orthop. 2013;7(1):3-9.

2. Parsch D, Gärtner V, Brocai DRC, Carstens C, Schmitt H. Sports activity of patients with idiopathic scoliosis at long-term follow-up. Clin J Sport Med. 2002;12(2):95-8.

3. Dolan $L A$, Weinstein SL. Surgical rates after observation and bracing for adolescent idiopathic scoliosis: an evidence-based review. Spine (Phila Pa 1976). 2007;32(19 Suppl):S91-100.

4. Watanabe K, Hasegawa K, Hirano T, Uchiyama S, Endo N. Use of the scoliosis research society outcomes instrument to evaluate patient outcome in untreated idiopathic scoliosis patients in Japan: part I: comparison with nonscoliosis group: preliminary/limited review in a Japanese population. Spine (Phila Pa 1976). 2005;30(10):1197-201.

5. Asher M, Min Lai S, Burton D, Manna B. Discrimination validity of the scoliosis research society-22 patient questionnaire: relationship to idiopathic scoliosis curve pattern and curve size. Spine (Phila Pa 1976). 2003:28(1):74-8.

6. Asher M, Lai SM, Burton D, Manna B. The influence of spine and trunk deformity on preoperative idiopathic scoliosis patients' health-related quality of life questionnaire responses. Spine. 2004;29(8):861-8.

7. Wilson PL, Newton PO, Wenger DR, Haher T, Merola A, Lenke L, et al. A multicenter study analyzing the relationship of a standardized radiographic scoring system of adolescent idiopathic scoliosis and the Scoliosis Research Society outcomes instrument. Spine (Phila Pa 1976). 2002;27(18):2036-40.
8. Weinstein SL, Dolan LA, Spratt KF, Peterson KK, Spoonamore MJ, Ponseti IV. Health and function of patients with untreated idiopathic scoliosis: a 50year natural history study. JAMA. 2003;289(5):559-67.

9. Bunge EM, Juttmann RE, de Kleuver M, van Biezen FC, de Koning HJ. NESC IO group. Health-related quality of life in patients with adolescent idiopathic scoliosis after treatment: short-term effects after brace or surgical treatment. Eur Spine J. 2007;16(1):83-9.

10. Danielsson AJ, Wiklund I, Pehrsson K, Nachemson AL. Health-related quality of life in patients with adolescent idiopathic scoliosis: a matched follow-up at least 20 years after treatment with brace or surgery. Eur Spine J. 2001; 10(4):278-88.

11. Julious SA. Sample size of 12 per group rule of thumb for a pilot study. Pharm Stat. 2005;4(4):287-91.

12. Noyes FR, Barber SD, Mooar LA. A rationale for assessing sports activity levels and limitations in knee disorders. Clin Orthop Relat Res. 1989:246:238-49.

13. Klepper SE. Measures of pediatric function: child health assessment questionnaire (C-HAQ), juvenile arthritis functional assessment scale (JAFAS), pediatric outcomes data collection instrument (PODCl), and activities scale for kids (ASK). Arthritis Care Res. 2011;63(Suppl 11):S371-82.

14. Stenton C. The MRC breathlessness scale. Occup Med (Lond). 2008;58(3):226-7.

15. Lee L, Friesen M, Lambert IR, Loudon RG. Evaluation of dyspnea during physical and speech activities in patients with pulmonary diseases. Chest. 1998;113(3):625-32.

16. Harshavardhana NS, Dormans JP. Review of patient reported outcome measures used in pediatric spinal deformity surgery. UPOJ. 2013;23(1):31-2.

17. SRS-22r Scored Sample (PDF). [ebook] spine deform; 2006. Available from: http://www.srs.org/Userfiles/file/outcomes/srs-22_sample.pdf.

18. Weinstein SL, Dolan LA. The evidence base for the prognosis and treatment of adolescent idiopathic scoliosis: the 2015 orthopaedic research and education foundation clinical research award. J Bone Joint Surg Am. 2015; 97(22):1899-903.

19. Bjure J, Grimby G, Kasalický J, Lindh M, Nachemson A. Respiratory impairment and airway closure in patients with untreated idiopathic scoliosis. Thorax. 1970;25(4):451-6.

20. Danielsson AJ, Ekerljung L, Hallerman KL. Pulmonary function in middleaged patients with idiopathic scoliosis with onset before the age of 10 years. Spine Deform. 2015;3(5):451-61.

21. Climent JM, Bago J, Ey A, Perez-Grueso FJS, Izquierdo E. Validity of the Spanish version of the Scoliosis Research Society-22 (SRS-22) patient questionnaire. Spine (Phila Pa 1976). 2005;30(6):705-9.

22. Merola AA, Haher TR, Brkaric M, Panagopoulos G, Mathur S, Kohani O, et al. A multicenter study of the outcomes of the surgical treatment of adolescent idiopathic scoliosis using the Scoliosis Research Society (SRS) outcome instrument. Spine (Phila Pa 1976). 2002;27(18):2046-51.

23. Weinstein SL, Zavala DC, Ponseti IV. Idiopathic scoliosis: long-term follow-up and prognosis in untreated patients. J Bone Joint Surg Am. 1981;63(5):702-12.

24. Goldberg MS, Mayo NE, Poitras B, Scott S, Hanley J. The Ste-Justine adolescent idiopathic scoliosis cohort study. Part II: perception of health, self and body image, and participation in physical activities. Spine (Phila Pa 1976). 1994;19(14):1562-72.

25. Altaf F, Gibson A, Dannawi Z, Noordeen H. Adolescent idiopathic scoliosis. BMJ. 2013:346(7906):30-4.

\section{Publisher's Note}

Springer Nature remains neutral with regard to jurisdictional claims in published maps and institutional affiliations.

Ready to submit your research? Choose BMC and benefit from:

- fast, convenient online submission

- thorough peer review by experienced researchers in your field

- rapid publication on acceptance

- support for research data, including large and complex data types

- gold Open Access which fosters wider collaboration and increased citations

- maximum visibility for your research: over $100 \mathrm{M}$ website views per year

At $\mathrm{BMC}$, research is always in progress.

Learn more biomedcentral.com/submissions 